\title{
THE EXPERIENCE OF EUROPEAN INTEGRATION AND THE POTENTIAL FOR INTEGRATION IN SOUTH AMERICA
}

\author{
$2007 / 6$ \\ \begin{tabular}{|l|l|}
\hline \multicolumn{1}{|c|}{ I } \\
\hline I & B \\
\hline E & I \\
\hline
\end{tabular} \\ I \\ INSTITUT \\ BARCELONA \\ INTERNACIONALS
}

Andrés Malamud

and Philippe C. Schmitter

Andrés Malamud

Institute of Social Sciences, University of Lisbon

andres.malamud@eui.eu

Philippe C. Schmitter

European University Institute, Florence

philippe.schmitter@eui.eu 


\section{IBEI WORKING PAPERS}

$2007 / 6$

The Experience of European Integration

and the Potential for Integration in South America

(C) Andrés Malamud and Philippe C. Schmitter

(C) IBEI, de esta edición

$\begin{array}{ll}\text { Edita: } & \text { CIDOB edicions } \\ & \text { Elisabets, } 12 \\ & 08001 \text { Barcelona } \\ & \text { Tel. } 933026495 \\ & \text { Fax. } 933022118 \\ & \text { E-mail: publicaciones@cidob.org } \\ & \text { URL: www.cidob.org }\end{array}$

Depósito legal: B-21.147-2006

ISSN:1886-2802

Imprime: Cargraphics S.A.

Barcelona, February 2007 


\title{
THE EXPERIENCE OF EUROPEAN INTEGRATION AND THE POTENTIAL FOR INTEGRATION IN SOUTH AMERICA
}

\author{
Andrés Malamud and Philippe C. Schmitter
}

\begin{abstract}
The experience of the European Union is the most significant and far-reaching among all attempts at regional integration. It is, therefore, the most likely to provide some lessons for those world regions that are just beginning this complex process. In turn, the Common Market of the South (MERCOSUR) and the Andean Community (CAN) are among the regional integration projects that have reached the greatest level of formal accomplishment after the EU. MERCOSUR is a customs union that aspires to become a common market, while avowing the commitment to advance towards political integration. For its part, CAN is a customs union that has already developed supranational institutions such as a Commission, a Parliament and a Court of Justice. In both cases, however, words have progressively tended to wander far from deeds. One reason underlying this phenomenon may be a misunderstanding of the European experience with integration. In this article, we discuss the theories that have been developed to account for integration in Europe and may prove useful to understand integration elsewhere and put forward a set of lessons that could be drawn from the European experience. Subsequently, we introduce a description of the experience of integration in South America and reflect (critically) on how the theories and lessons drawn from the EU could be applied to this region -and beyond.
\end{abstract}

Key words: Regional Integration, Integration Theories, Comparative Regionalism, European Union, Mercosur, Andean Community.

Previous versions of this paper were delivered at the Joint Sessions of Workshops of the European Consortium for Political Research (ECPR), Nicosia, 25-30 April 2006, and at the Workshop on Comparative Regionalism in World Politics: Benchmarking Best Intellectual Practice, Institute for International Economic Relations, Athens, 11-12 December 2006. We are grateful to Ben Rosamond, Alex Warleigh and the other participants of the workshops, who are not responsible for any errors that remain. 


\section{Introduction}

The recent experience of Europe with efforts at integrating-peacefully and voluntarilypreviously sovereign national states into a single transnational organization, the European Union (EU), is by far the most significant and far-reaching among all attempts at regionalism. It is, therefore, the most likely to provide some lessons for those world regions that are just beginning this complex and historically unprecedented process.

The Common Market of the South (MERCOSUR) and the Andean Community of Nations (CAN) are regional integration projects that have reached the greatest level of formal accomplishment after the EU. MERCOSUR is formally a customs union that aspires to become a common market, while avowing the commitment to advance towards political integration. For its part, CAN is a customs union that has already developed supranational institutions such as a Commission, a Parliament and a Court of Justice. In both cases, however, words have progressively tended to wander far from deeds in what has been called a case of "cognitive dissonance" (Malamud 2005b). One reason underlying this phenomenon may be a misunderstanding of the European experience with integration.

This article proceeds as follows. First, we discuss the integration theories that have been developed to account for integration in Europe and may prove useful to understand integration elsewhere. Second, we put forward a set of lessons that could be drawn from the European experience. Third, we introduce a brief account of the experiences of MERCOSUR and CAN. Fourth, we reflect (critically) on how the theories and lessons drawn from the EU could be applied to South America — and beyond.

\section{Theories to be Explored'}

There is only one instrument that can help us to transfer knowledge and lessons from one experience with regional integration to the other: theory. Only by capturing the generic concepts, confirmed hypotheses, and observed processes underlying the European experience can we expect to make any contribution to understanding the conditions under which MERCOSUR might succeed. And, even then, given the substantial differences in cultural norms, historical experiences, social structures, geo-strategic location and political regimes, there are abundant reasons to be cautious when transferring such lessons-as we shall see.

Unfortunately, there exists no dominant theory of why and how European regional integration works. It is surprising that a process that has been studied in such concrete detail continues to generate such abstract controversy. There is relatively little disagreement over the facts or even over the motives of actors, but there is still no single theory that can adequately explain the dynamics (or even the statics) of such a complex process of change in the relationship between previously sovereign national states and persistently more interdependent national economies, societies and polities.

The theory or, better, approach that we shall primarily draw upon in the next section for formulating lessons concerning MERCOSUR is something called "neo-functionalism." It places major

${ }^{1}$ The following part contains segments drawn from Schmitter (2004). 
emphasis on the role of non-state actors-especially, the "secretariat" of the regional organization involved and those interest associations and social movements that form at the level of the region-in providing the dynamic for further integration. Member states, however, remain important actors in the process. They set the terms of the initial agreement, but they do not exclusively determine the direction and extent of subsequent change. Rather, regional bureaucrats in league with a shifting set of selforganized interests and passions seek to exploit the inevitable "spill-overs" and "unintended consequences" that occur when states agree to assign some degree of supranational responsibility for accomplishing a limited task and then discover that satisfying that function has external effects upon other of their interdependent activities. According to this theory, regional integration is an intrinsically sporadic and conflictual process, but one in which, under conditions of democracy and pluralistic representation, national governments will find themselves increasingly entangled in regional pressures and end up resolving their conflicts by conceding a wider scope and devolving more authority to the regional organizations they have created. Eventually, their citizens will begin shifting more and more of their expectations to the region and satisfying them will increase the likelihood that economic-social integration will "spill-over" into political integration (Haas 1958, 1964). ${ }^{2}$

Among those studying the EEC/EC/EU, neo-functionalism is, by no means, uncontested in its capacity to explain ex post or to capture ex ante the sinuous path of European integration. Indeed, it has been one of the most frequently misunderstood, caricatured, pilloried, and rejected of all such theories. To the extent that there is a dominant theory among North American political scientists, it tends to be something called "intergovernmentalism"-probably, because most of those in the US who have examined the EU have approached it from the perspective of international relations where the reigning orthodoxy, neo-realism, translates almost without modification into the idiom and assumptions of intergovernmentalism. From this perspective, the message is simple: power matters and state power matched to national interest matters absolutely! The direction and pace of regional integration will be determined by the interaction of sovereign national states, which not only control the initiation of the integration process but also all of its subsequent stages. Whether the process moves forward or backward or stagnates depends on calculations of national interest and the relative power that can be brought to bear on any specific issue. Under no conceivable circumstances could this process transform the nature of its member states. Indeed, its purpose is to strengthen not weaken those states (Hoffmann 1966; Moravcsik 1998).

Europeans have tended to approach the EU more frequently from the perspective of comparative politics, and this helps to explain why they opt for other approaches-while still not agreeing on a dominant one. For example, the original approach after World War II was federalism (Burgess 1989), mostly borrowed from the American experience. Long confined to the margin as an item of ideological wishful thinking, it was revived with the convocation by the EU of a Convention on the Future of European Institutions and the drafting of a so-called Constitutional Treaty-only to be subsequently arrested by popular referendums in France and the Netherlands. A fourth "generic" approach currently well represented in Europe places its emphasis on the regulatory nature of EU policies. Interestingly, it too draws much of its inspiration from the US or, better, from the national government's practice of "independent regulatory agencies," but projects its notions and observations to the supranational level. It shares with neo-functionalism the attention to micro- and meso-exchanges between sub-national actors, eschewing the exclusive emphasis that intergovernmentalism gives to

${ }^{2}$ On at least two different occasions, Haas $(1971,1975)$ disavowed his creation. More recently, Schmitter has attempted to revive it in the article cited above. 
treaties or that federalism gives to constitutions, but it denies any transformative potential. Supranational regulation is seen as a technocratic imperative generated by highly interdependent economies and societies, but not something that changes the basic nature or autonomy of national politics (Majone 1996).

However, as one can see in Figure 1, there are many other candidates for the job of explaining and, thereby, producing generic lessons about regional integration. Especially since it was re-launched in the mid-1980s with the Single European Act, the EU has become once again a very lively site for theoretical speculation. Hardly a year does not pass that someone does not come up with a new theory and, even more surprisingly, manages to convince another group of scholars to produce a collective volume extolling its virtues. "International regime analysis," "the regulatory approach," "liberal intergovernmentalism," "the policy-network approach," "the fusion-thesis," "multi-level governance," "institutionalism," "rationalism," "constructivism," "reflectivism" and "post-modernism" have all followed each other over the past years and managed to find themselves a place somewhere in Figure 1.

\section{Figure 1}

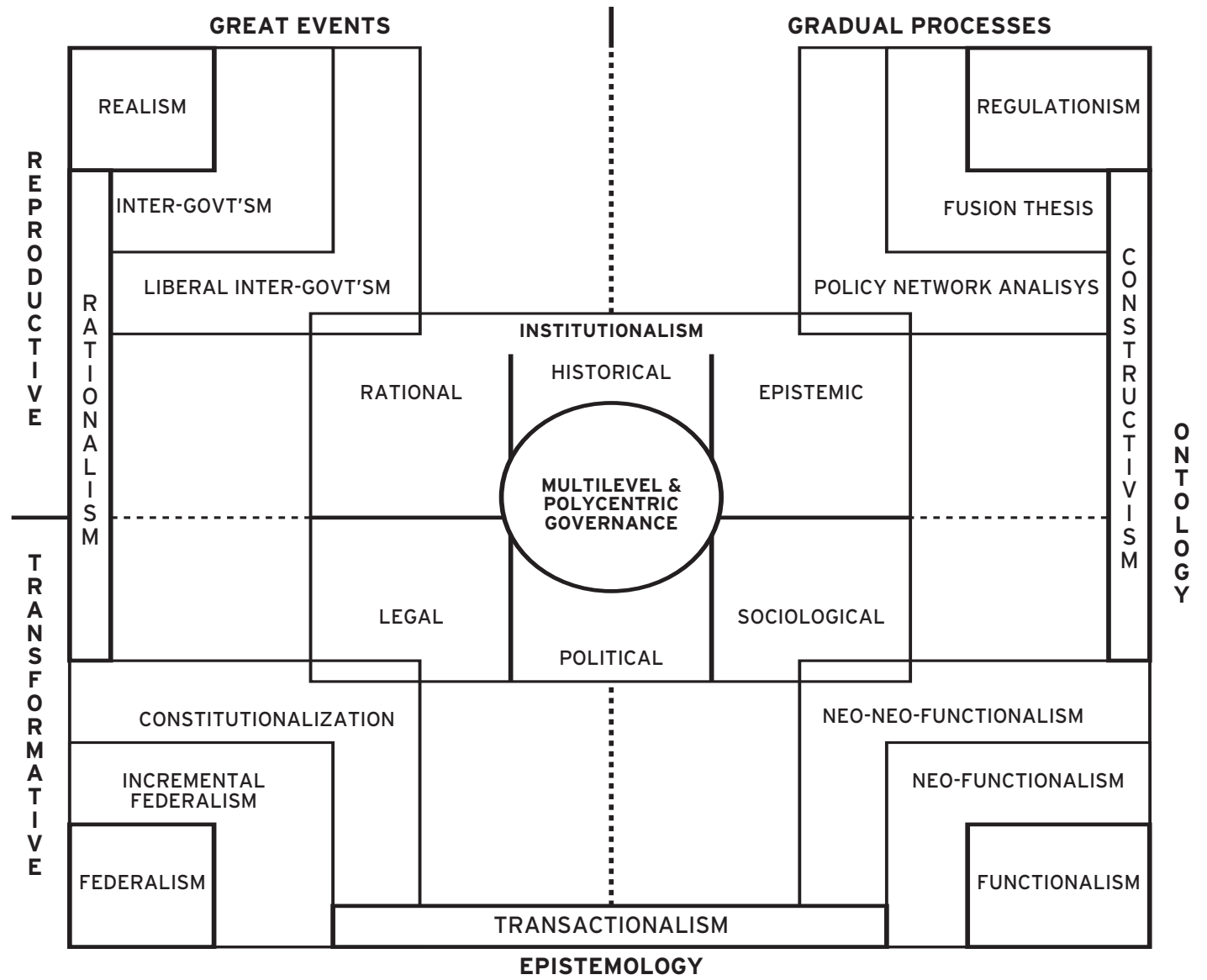

Nor are these disputes over concepts and assumptions purely academic. As we shall see, one is likely to draw very different lessons for other world regions from each of these theories/approaches. One of the main tasks of any scholar trying to assess the prospects of integration in MERCOSUR will be to select that theory (or theories) in Figure 1 that is or are most apposite for the peculiar conditions of his or her embryonic region. 
All theories of regional integration could be placed somewhere within a two dimensional property space formed by the following variables:

1. Ontology: whether the theory presumes a process that reproduces the existing characteristics of its member-state participants and the interstate system of which they are a part, or presumes a process that transforms the nature of these sovereign national actors and their relations with each other; and

2. Epistemology: whether the evidence gathered to monitor these processes focuses primarily on dramatic political events, or upon prosaic socio-economic-cultural exchanges.

Figure 1 fills that property space with real-live "isms" that have been applied at different moments in time and from different disciplinary perspectives to explaining the dynamics (and statics) of the EU. Appropriately, we find functionalism with its neo- and neo-neo-versions in the bottom righthand corner of the plot. Its ontology is transformative in that it assumes that both actors and the "games they play" will change significantly in the course of the integration process; its epistemology is rooted in the observation of gradual, normal and (by and large) unobtrusive exchanges among a wide range of actors. Its historic opponent, realism with its pure intergovernmental and liberal intergovernmental modifications, is diametrically opposite since its key assumptions are that dominant actors remain sovereign national states pursuing their unitary national interests and controlling the pace and outcome through periodic revisions of their mutual treaty obligations. Federalism is another transformative option, but it too relies on episodic "moments" at which a multitude of actors (and not just their governments) agree upon a new constitutional format. Its diametrical opposite is what may be labeled "regulation-ism." It shares with intergovernmentalism the presumption of fundamental continuity in actors with only a shift upward in the level at which regulation occurs. The member-states, however, remain the same as does their motivation and their predominant influence over the process. The empirical focus differs in that, like functionalism, it emphasizes almost exclusively socio-economic exchanges and the "normal" management of their consequences.

In the center of the property space of Figure 1, we find an enormous and amorphous thing called "institutionalism." Most of the growth in recent theorizing about European and regional integration more generally proudly proclaims itself as such -and then immediately alerts the reader to the fact that there are many different versions of "it." By Schmitter's (2004) account, there are six: (1) a "rational" one that overlaps loosely with liberal intergovernmentalism in its insistence on unitary actors, marginalist calculations and credible commitments; (2) a "legal" one that stresses the gradual but intrusively federalist role of juridical decisions and precedents; (3) a "historical" one that emphasizes the "stickiness" of identities and the "path-dependency" of institutions, but is not insensitive to less obtrusive processes of change; (4) an "epistemic" one that focuses on the normative and professional communities that cluster around specific issues-arenas and influence the making and implementing of regulations; (5) a "political" one that locates a source of potential transformation in the interpersonal networking of key politicians and their relative autonomy from followers; and, finally (6) a "sociological" one that overlaps with neo-neo-functionalism in its emphasis on the formation of transnational class, sectoral and professional associations and the contestation generated by global and regional social movements. Whether any or all of these deserve the prestigious title of "theory" is a matter of dispute. Institutionalism, as such, has only minimal content ("institutions matter" seems to capture and exhaust it), but some of its sub-types at least deserve the label of an approach.

In the very center of that amorphous thing in Figure 1 called "institutionalism" appears "MultiLevel Governance (MLG)." MLG can be defined as an arrangement for making binding decisions that 
engages a multiplicity of politically independent but otherwise interdependent actors-private and public-at different levels of territorial aggregation in more-or-less continuous negotiation/deliberation/implementation, and that does not assign exclusive policy compétence or assert a stable hierarchy of political authority to any of these levels.

It is also apposite to stress the "poly-centric" as well as the "multi-level" nature of the EU in order to include the functional dimension along with the territorial one. Poly-Centric Governance (PCG) can be defined as an arrangement for making binding decisions over a multiplicity of actors that delegates authority over functional tasks to a set of dispersed and relatively autonomous agencies that are not controlled—de jure or de facto—by a single collective institution.

MLG has become the most omnipresent and acceptable label one can stick on the contemporary EU. Even its own politicians use it! Probably, its popularity among theorists can be attributed to its descriptive neutrality and, hence, its putative compatibility with virtually any of the institutionalist theories and even several of their more extreme predecessors. For politicians, it has the singular advantage of avoiding the controversial term: "state" (especially, "supranational state") and, therefore, sounds a lot less forbidding and threatening. For example, the emergence of the MLG+PCG from the process of European integration can be explained (in part) by almost all of the theories in Figure 1.

\section{Lessons to be (Cautiously) Transferred}

The "lessons" sketched out below have been drawn, primarily but not exclusively, from a neofunctionalist "reading" of the sinuous course of European integration. We think that this approach offers the best understanding of its long-term processes-with one, very important, caveat. The initiation of regional integration clearly requires an explicit agreement among governments. No one can deny that the institutions and compétences that they endow it with initially will have a continuous impact on its subsequent trajectory. Moreover, there is a high likelihood that the national states that agree to such a founding treaty will do so with the expectation that it will protect and even strengthen their sovereignty, not transform it. What happens subsequently, once the process of integration has kicked in and begun to generate its intended and unintended consequences, can be quite another matter.

\section{Regional integration is a process not a product.}

Once it has begun, the peaceful and voluntary integration of previously sovereign national states can proceed in a multitude of directions and produce secondary and tertiary effects not imagined by those who initiated it. Precisely because it has been such an infrequent occurrence, no one can predict how far it will go and what its eventual result will be. Moreover, once national states have made a serious commitment to forming a "region," they are very likely to change their motives for doing so. They may begin with security and geo-strategic reasons (Western Europe did so) and then find other applications for their "joint venture," i.e. economic prosperity and, more recently and more conflictually, unity of political action. There is no assurance that the initial effort will succeed (indeed, most attempts at regional integration have failed). Depending on conditions prevailing within and between member states, it can just as well "spill-back" as "spill-over" - to use the jargon of neofunctionalism. However, under certain conditions (and Western Europe seems to have fulfilled them), actors are more likely to resolve the inevitable conflicts of interest that emerge from the integration process by enlarging the tasks and expanding the authority of their common, supranational institutions. This, in essence, is the core of the neo-functionalist approach. 


\section{Regional integration has to begin somewhere and the best place to do so under} contemporary conditions is with a functional area that is of relatively low political visibility, that can apparently be dealt with separately and that can generate significant benefits for all participants.

After experimenting unsuccessfully with the "direct" route to integration via common political or military institutions, the Europeans tried a second-best, indirect one-and it has (more or less) worked. The contemporary point of departure is likely to be different (the Europeans started with coal and steel; no one today would even think of this combination), but the strategy is well captured by Jean Monnet's phrase: "Petits Pas, Grands Effets," loosely translated as, "Take small steps that will lead to large effects." One wants a concrete task that can be jointly managed with little initial controversy, but which is sufficiently linked to others so that it generates secondary effects upon other areas of potential joint cooperation. The gamble is that the conflicts generated by trying to fulfill this initial task will be resolved positively. In the case of the EU, sectoral integration was followed by trade liberalization and the Common Agricultural Program (CAP) and, only belatedly, by monetary integration. Elsewhere, the sequence may be different, but the important point is the need to start out with something that involves cooperation to solve concrete problems in a positive fashion. Trade liberalization alone is very unlikely to produce such "spill-over" effects. ${ }^{3}$

\section{Regional integration is driven by the convergence of interests, not by the formation of an identity.}

International regions are artificial constructs. They are produced not found. Some of the clusters of national states that share the most in terms of language, religion, culture and historical experience have been the least successful in creating and developing organizations for regional integration, e.g. the Middle East and North Africa, West and East Africa, Central and South America. Ironically, it has been Europe with its multiple languages, firmly entrenched national cultures and dreadful experience with armed conflict that has proceeded the furthest-although it is important to note that the process of its regional integration has become increasingly controversial and no one has yet been able to discern where, when, and with whom it will end. If nothing else, the EU demonstrates that it has been possible "to make Europe without Europeans." Those who anticipated that concerted effort at solving concrete problems, increased economic interdependence or facilitated social communication across national borders would produce a decline in national identities and an upward shift in loyalties have been frustrated. Granted that the salience of national identities has declined (except when it comes to football matches) and that Europeans seem comfortable with multiple, nested identities that also descend to the sub-national as well as ascend to the supranational level. Granted also that the personal life styles, modes of social behavior and norms of political action have converged within Europe. Whether this has been the product of the integration process or of a broader worldwide diffusion centered on the US is a matter of dispute. Those such as Ernst Haas who foresaw a shift in loyalty to the supranational level are bound to be disappointed; those who only expected a shift in attention to the EU level are satisfied when integration inserts an enduring and significant focus of interest. Who knows how, when or even whether regionalism will transcend national identities, the important thing in the meantime is that Europeans know, understand and accept that many of their interests can only be satisfied by processes that transcend national borders.

\footnotetext{
3 Schmitter (1970a: 243) has defined this "spill-over hypothesis" in the following way: "Tensions from the global environment and/or contradictions generated by past performance (within the organization) give rise to unexpected performance in pursuit of agreed-upon objectives. These frustrations and/or dissatisfactions are likely to result in the search for alternative means for reaching the same goals, i.e. to induce actions to revise their respective strategies vis-à-vis the scope and level of regional decision-making".
} 


\section{Regional integration may be peaceful and voluntary, but it is neither linear nor exempt from conflict.}

The neo-functionalist strategy (also known in Euro-speak as "the Monnet Method") involves focusing as much as possible on low visibility and less controversial issues that can be separated from normal, i.e. party, politics. As interest conflicts arise, they are decomposed and then recomposed into so-called "package deals" that promise benefits for all and compensate the prospective losers with sidepayments in other domains. Regardless of the formal rules, and even now that qualified majority voting applies to a wider and wider range of issues, every effort is made to reach a consensus. When such a solution cannot be found, the decision-making aspect of the integration process simply goes into hibernation for an indeterminate length of time. Meanwhile, the processes of expanded exchange continue to produce their intended and unintended effects and, eventually, the participants return to the table. The most visible aspect of the process has been the periodic negotiation of new treaties. Important as these may be, they are but the surface manifestation of a much more extensive process that has facilitated exchanges between individuals, firms and associations in virtually all domains of social, economic and political life and resulted in the creation of a large number of public and private organizations at the European level. Whether this strategy can persist is highly problematic. The EU has run out of low visibility arenas for policy coordination and the issues that it is currently facing, e.g. fiscal harmonization, visa and asylum requirements, police cooperation, common foreign and security policy, can be quite controversial. The increasing difficulty with the ratification of treaties that have been approved by all member governments is a clear sign of "politicization" and its penetration of domestic partisan politics.

\section{Regional integration should begin with a small number of member states, but should from that beginning announce that it is open to future adherents.}

Moreover, it is desirable that this initiating group form a "core area" to use Karl Deutsch's term; that is, they should be spatially contiguous and have a high rate of mutual exchange amongst themselves. If the functional area and members are well chosen, this should result in a differentially greater increase in exchanges among themselves and a discriminatory treatment of those who have been left outside. Provided that they agree on the internal distribution of benefits and do not generate permanent factions (not an easy task), their relative "success" will attract those neighboring states that chose initially not to join the region. The process of incorporating new members places a heavy burden on institutions, but becomes a manifest symbol that the "region" is worth joining. Especially crucial is the ability to protect the acquis when enlarging and not to dilute the accumulated set of mutual obligations as a way of satisfying specific interests in the new member states. It is important to remember that "regions" do not pre-exist in some cultural, social or economic sense. They have to be created politically out of existing "raw material."

\section{Regional integration inevitably involves national states of quite different size and power capability.}

Since it is a voluntary process, the largest and most powerful members cannot simply impose their will —as they would do in an imperial system. They have to respect the rights and presence of the smaller and weaker units. At a minimum, this implies firm guarantees for their continued existence, i.e. that the integration process will not involve their being "amalgamated" into larger ones, and this seems to require that smaller units be systematically over-represented in regional institutions. Moreover, there is a distinctive and positive role for smaller states to play in the integration process, especially when they can act as "buffer states" between larger ones. Not coincidentally, the citizens of those states that were smaller and less developed when they entered the EU tend to be among the stronger supporters of the EU. 


\section{Regional integration, however, requires leadership, i.e. actors who are capable of taking initiatives and willing to pay a disproportionate share of the cost for them.}

The European experience suggests that this role is better played by a duopoly (France and Germany) rather than either a single hegemonic power (Germany) or a triopoly (Germany, France and Great Britain). Moreover, it is crucial that these leading regional actors accept to under-utilize their immediate power capability (pace neo-realism and intergovernmentalism) in order to invest it in a long run strategy of legitimating the enterprise as a whole. Fortunately for the integration of Europe, the potential hegemon (Germany) had just suffered a disastrous defeat in war and was pre-inclined to downplay its role. France, the ex-great power, has found this more difficult and its tendency to selfmaximize has repeatedly threatened the process of consensus formation.

\section{Regional integration requires a secretariat with limited but potentially supranational powers.}

Not only must this organization not be perceived as the instrument of one of its (hegemonic) members, but it also must possess some degree of control over the agenda of the process as a whole. The EU Commission is composed of members selected by an obscure process, firmly rooted in nomination by national governments, but presumed once approved to owe their allegiance to the supranational integration process and, therefore, not to take instructions from the body that chose them. There is evidence that, however flawed the nomination procedure, the Commissioners do tend to acquire a "collegial" perspective and to act as supranational agents. Moreover, the President of the Commission can under admittedly unusual circumstances not only assert his monopoly over the introduction of new measures, but also play a proactive role in determining what these measures should be.

\section{Regional integration requires that member states be democratic.}

This is a factor that virtually all theories of European integration have taken for granted-as did the earlier practitioners until in the early 1960s when the application of Franco Spain for EEC membership made them explicitly stipulate that "domestic democracy" was a prerequisite to joining. In the Treaty of Amsterdam (1998) this was extended to cover respect for human rights and the rule of law. Obviously, when transferring the lessons of integration "out-of-region," this can no longer be taken for granted. Virtually all other regions in the world have some non-democracies within them. There are (at least) three reasons why democracy is necessary: (1) Only governments that have strong legitimacy within their respective national societies can make the sort of "credible commitments" that are necessary for them to enter into agreements, to ratify them conclusively, and to monitor their eventual implementation. (2) The presence of a democratically accountable government within all members is a supplementary assurance that none of them will resort to force in resolving disputes. Whatever temptation more powerful governments might have to extract concessions by threatening weaker recalcitrant members, it seems unlikely that this would be supported by their own citizens. (3) If the neo-functionalists are right, a key element driving the integration process forward will be the formation of transnational interest associations and social movements and their intervention in supranational policymaking. Only in national democracies will citizens have the freedoms needed to organize such forms of collective action and to create links with others across national borders.

\section{Regional integration seems possible with members that are at different levels of development and per capita wealth.}

At the beginning, in the EEC only Italy was markedly poorer and less developed. The subsequent incorporation of Ireland, Greece, Portugal and Spain re-confirmed the EU's capacity not just to accommodate to this obvious source of tension, but also to react to it. Through a combination of policies-selective derogations at entry, regional and structural funds, agricultural subsidies and the 
sheer dynamics of wider competitive markets-it promoted a pattern that could be called "upward convergence." Those member states (and even their less developed and poorer sub-national regions) that entered under less favorable conditions tended to do better subsequently and their standards of living have converged toward the EU norm (and in one case, Ireland, even exceeded it)—without, however, noticeably depressing the performance of the more favored member states. The recent addition of 10 members is going to test this fortunate pattern severely. The initial differences in poverty and underdevelopment are greater than in past enlargements and, in some cases, this is compounded by structural differences in managerial and property relations rooted in the transition from "realexisting" socialism to "real-existing" capitalism. Nevertheless, contrary to the doctrinal assumption that integration into an enlarged market would inevitably widen the gap between wealthy and poor unitsvide the national histories of Italy and Spain-so far, the EU has proved the contrary. Regional integration can not only cope with national economic differences at the point of departure, but also diminish them over time.

\section{Regional integration is basically an endogenous process, but it can be critically vulnerable to exogenous forces, especially in its initial stages.}

Once a subset of national states has agreed to create a "region" by accepting certain mutual obligations and endowing a common organization with specified powers, its subsequent success or failure is primarily a matter of exchanges between these member states, plus the influence of non-state actors within and increasingly across their borders. Obviously, the more the initial powers delegated to the regional organization, the more important will be the role of its leadership and administration. The European experience, however, suggests that in its early stages regional integration can be very dependent on external powers. More precisely, it is doubtful that the process would have even begun with the Coal and Steel Community in 1952 and the Economic Community in 1958 without the benevolent intervention of the US. Here is where the "realist" perspective and its "intergovernmental" cousin should be especially relevant. Presumably, there exists a configuration of power and interest in the broader world system that determines if and when an exogenous hegemonic actor will conclude that it would prefer that its rivals be integrated rather than disintegrated. On the face of it, this seems contrary to the classical doctrine of "divide et impera," i.e. the stronger you are, the more you wish that your opponents are divided-lest they gang up to countermand your dominance. Obviously, the overriding imperative in the case of Western Europe in the 1950s was fear of the Soviet Union. But now that this imperative no longer exists (and has not yet been replaced by fear of China), the implication seems clear: the US will be much less likely to view favorably movements toward regional integrationat least, those that it does not participate in or cannot control.

\section{Regional integration, at least until it is well established, is a consumer not a producer of international security.}

To make sense of this affirmation one has to make a distinction between regional defense pacts and regional integration organizations. The former, usually the product of a hegemonic power that spreads its defense capability over that of subordinate others, e.g. the US and NATO, the Soviet Union and the Warsaw Pact, is exclusively oriented towards protecting the external sovereignty of its participants by military means; the latter's purpose is to supplant or, at least, to pool the internal sovereignty of its participants by removing barriers to economic, social and political exchange. In Western Europe, membership in the two was not coincident and definitely not obligatory. The EEC/EC/EU was fortunate in its early decades to have existed "in the shadow of NATO" and, therefore, not to have had to add external security to its already controversial agenda. With the collapse of the barrier between Western and Eastern Europe and the end of the Cold War, NATO's role has become increasingly ambiguous and EU member states have begun to elaborate their own capability 
for collective security. Given the enormous difficulty of such a task, it has been suitable that their "civilian" regional institutions are already well established and recognized-if not always beloved. What is much more crucial for the success of regional integration is the existence among member states of what Karl Deutsch called a "pluralistic security community" (Deutsch et al. 1957) This does not require common formal institutions, as would a viable military alliance (indeed, it can exist with allied and neutral members), but involves a firm and reliable, if informal, understanding that under no foreseeable circumstances will its members either use or threaten to use military force in the resolution of disputes among them. "Domestic democracy" in all member states is part of this mutual assurance (along with respect for the rule of law), but it is the daily practice of making deals and reaching consensus within regional organizations that makes this understanding credible.

\section{Past and Present of South American Integration ${ }^{4}$}

Latin American integration has a long history according to conventional political rhetoric, but a poor record when it comes to concrete accomplishments. The region was previously ruled by two colonial powers, both located on the Iberian Peninsula. Gradually, the territory dominated by the Spanish crown was divided in two, later into four and then successively into a dozen autonomous regions, a process that culminated in the establishment of the nineteen independent, Spanish-speaking states in existence today. Even as the process of fragmentation evolved, the leaders of the wars of independence nurtured the myth of Latin America's natural unity and the ultimate aim of restoring it. Simón Bolívar, the best known of these leaders, called two Pan-American congresses in 1819 and 1826, but failed to bring about regional unity. Almost two centuries later, with the failure of reiterated unification attempts, the Pan-American movement waned and was gradually superseded by a less ambitious but more realistic project: that of regional integration.

The first serious effort to promote regional integration occurred in 1960 with the creation of the Latin American Free Trade Association (LAFTA). Twenty years later, given its poor performance it was replaced by the Latin American Integration Association (LAIA), with slightly better but still unremarkable results. Various sub-regional integration efforts were also made: the Central American Common Market (CACM) was established in 1960; the Andean Pact and the embryo of the Caribbean Community were set up in 1969; and in 1991, MERCOSUR was created. These four groups scored some early points, but then stagnated or decayed.

The Andean Pact, predecessor of CAN, was established in 1969 within the framework of LAFTA. Its goals were to improve the conditions for participation of the less developed countries encompassed by the LAFTA agreements, while simultaneously aiming at the gradual formation of a Latin American Common Market. Five countries signed its founding treaty, the Cartagena Agreement: Bolivia, Colombia, Chile, Ecuador, and Peru. Venezuela joined the group in 1973, but Chile withdrew in 1976. However, the Andean Group did not acquire juridical autonomy until 1983, when the Tratado de Creación del Tribunal de Justicia del Acuerdo de Cartagena entered into force.

${ }^{4}$ The following part contains segments drawn from Malamud (2004, 2005b).

${ }^{5}$ LAFTA and LAIA comprised the ten Latin American countries of South America plus Mexico and Cuba. 
The emergence of the Andean Pact was a direct response to LAFTA's failure, and its integration scheme was more far-reaching than anything ever before realized in this field in all of the Third World (Mace 1988). Two main features characterized the project. At the economic level, it relied on two parallel processes: inter-regional trade liberalization and regional industrial planning. At the political level, it created a decision-making structure including two main institutions, the Commission and the Junta, whose respective majority-rule voting and binding supranational authority were as ambitious as exceptional. ${ }^{6}$

Although the Andean Pact performed quite satisfactorily in its early years, the enlargement to Venezuela and the withdrawal of Chile generated a succession of major crises. Given the complexity of the Andean integration scheme, those events led to the renegotiation of some important mechanisms of the process and, in the end, to the complete abandonment of the original integration schedule (Mace 1988). Apart from the rigidity of the Agreement, the failure was due to other reasons, among which the unequal distribution of costs and benefits, the politicization of integration issues, the non-compliance of the member countries with the Andean Decisions (Vargas-Hidalgo 1979), deep political instability, ${ }^{7}$ and the lack of regional leadership (Mattli 1999). While some causes were basically domestic, others were intrinsic to the integration process. One of the recipes proposed to overcome the crisis was to build up regional institutions able to settle conflicts between members, and so was done. The result was the creation of the Court of Justice and the Andean Parliament in 1979. ${ }^{8}$ However, these institutions lacked real weight -due to, in neofunctionalist terms, the precedence of form over function. In 1987, the Quito Protocol was signed in order to make more flexible the working mechanisms of the bloc.

The renewed institutional structure of the Andean Pact was broader and deeper than that of any other region in Latin America. Nevertheless, it was not until all presidents met in 1989 that the region embarked on a process of further deepening and opening; and the setting of the Andean Presidential Council in 1990 was to consolidate such a bid. The Presidential Council is comprised by the presidents of the member countries, and constitutes the highest-level body of the Andean Integration System (AIS). In turn, the AIS is the series of bodies and institutions that, working in coordination, directs the process of integration and governs over its operation.

Today, the legal principle of direct effect and the preeminence of the community law make of the Andean Community the second region in the world according to the level of formal institutionalization, only behind the European Union. Its economic record, however, is far less impressive. Although a free trade zone is in force since 1993 and a common external tariff is operative since 1995, not economic development but social turmoil, political instability and economic failure have been the mark of the region. The balance of the process could not be more ambiguous: despite the highly institutionalized organization and the commitment to establish a common market by the year 2005 at the latest, the Andean countries have not yet succeeded in creating a region of peace, stability and development. As a result, some of them have opted for negotiating complementary agreements with third countries or regions, while Venezuela has simply left the bloc to join MERCOSUR. Consequently, regional institutions have remained feeble and intra-regional interdependence got stalled (Bonilla 2001).

6 Within the intergovernmental Commission, responsible for all the major decisions concerning the integration process, no member country was allowed to unilaterally veto community decisions except on very important subjects. In turn the Junta, endowed with administrative, agenda-setting, and decisionimplementation functions, enjoyed supranational powers that entitled it to take resolutions binding on all member countries -at least formally (Mace 1988).

7 By the early 1970s, all founding members except Colombia were undergoing democratic breakdowns.

8 The Court entered into activity in 1983; the Parliament is still comprised of a mix between delegates of the national congresses and directly elected representatives. 
MERCOSUR was created in 1991 by the Treaty of Asunción, which brought together Argentina, Brazil, Paraguay and Uruguay. Although the original goal of Presidents Alfonsín (Argentina) and Sarney (Brazil) was to provide support for their fledgling democratic regimes by lessening domestic pressures for greater military spending and increasing social welfare through international cooperation, the Treaty abstained from referring to political institutions or social actors. Instead, it focused exclusively on economic and commercial issues.

The Protocol of Ouro Preto, signed in 1994, gave MERCOSUR a formal institutional structure that was to remain untouched for the subsequent decade. The Protocol also gave MERCOSUR an international legal personality and defined its juridical bases. However, the bloc has not become a common market. At best, it established the blueprints for a customs union that is still far from complete (Bouzas, Motta Veiga and Torrent 2002).

The Treaty of Asunción and the Protocol of Ouro Preto, together with another three Protocols, ${ }^{9}$ constitute the institutional skeleton and juridical backbone of MERCOSUR. They deal with economic integration (content) and organizational structure (form). They do not deal with aspects that have acquired greater relevance in the EU such as regional citizenship, social cohesion and democratic decision-making. Somewhat surprisingly, however, these issues have been and still are present in nearly all debates about MERCOSUR.

The presidents and foreign ministers of MERCOSUR member countries have referred to it as a "strategic alliance," "destiny rather than choice," "the dynamic axis of South American integration," and even as "the most transcendental political decision in our history" (see Malamud 2005b). Lower ranking officials tend to use less lofty language but it is the highest authorities, particularly the presidents of the two largest members, who define the contours of the public image of MERCOSUR. After the global financial crises of 1995-1999, MERCOSUR came to be seen as a symbol of resistance to neo-liberalism. It has even been considered as a prototypical association of developing countries that could stand in the way of a US promoted hemispheric free trade area. For progressive ideologues, it has acquired an "epic" status as a preferred tool for promoting social rather than merely economic goals. Its battle cry has been for the creation of "a political MERCOSUR" (el MERCOSUR politico) that would be able to combat the neo-liberal approach to regional integration. The argument is that the original agreements signed by Argentina and Brazil in 1985-1988 were perverted in the 1990s, transforming what had been a progressive state-led initiative into a conservative market-based project. A return to the original intent would involve bringing political objectives to the fore, i.e. by prioritizing the social and representative dimensions of regional integration as opposed to its trade and investment aims. In this context, recurrent references have been made to the participation of civil society and the establishment of a regional parliament. We contend that these appeals, well-intended as they may be, fail to grasp the lessons derived from the European experience that most ideologues are so fond of invoking.

MERCOSUR was intentionally created and maintained as an intergovernmental organization. Its founders did not want to replicate the failures of previous attempts at integration in Latin America, especially the experience of the Andean Pact. Hence, they insisted that all decisions would have to be made through a process that exclusively involved national officials with unanimous consent as the only

9 They are the Protocol of Brasilia (establishing a system for dispute settlement and signed in 1991), the Protocol of Ushuaia (establishing a democratic clause and signed in 1998), and the Protocol of Olivos (establishing a permanent tribunal for appeals and signed in 2002). 
decision rule. As there is neither community law nor direct effect, all significant decisions have to be transposed into the domestic legislation of every member country to take effect. Furthermore, policies can only be implemented at the national level by national officials, as there is no regional bureaucracy. Dispute-settlement is the only area that has been formally excluded from the requirement for intergovernmental consensus, although the mechanisms established by the Protocol of Brasilia have been called upon only ten times in 15 years-in contrast to the over hundred rulings made every year by the EU Court of Justice. As has been pointed elsewhere, MERCOSUR appears to incarnate an extreme type of intergovernmentalism: "interpresidentialism" (Malamud 2003, 2005a). Interpresidentialism is the outcome of combining an international strategy, presidential diplomacy, with a domestic institutional structure, presidential democracy. It consists of resorting to direct negotiations between national presidents who, making use of their institutional and political capabilities, intervene on regional affairs every time a crucial decision has to be made or a critical conflict needs to be solved. Thus far, low levels of previous interdependence associated with interpresidential dynamics have kept MERCOSUR working but prevented spillover from taking place (Malamud 2005c).

Lately, some projects have been advanced with the aim of placing MERCOSUR on the track towards deeper integration. The introduction of IIRSA (Initiative for the Integration of South American Regional Infrastructure) in 2000, the creation of a Committee of Permanent Representatives in 2003, the foundation of a permanent Court of Appeals in 2004, the establishment of FOCEM (Fund for MERCOSUR Structural Convergence) in 2005, and the foreseen creation of a common Parliament in 2007 seem to be steps in that direction. At the same time, a more ambitious initiative aimed at integrating the whole subcontinent has been launched: the South American Community of Nations (SAC). We will come back to them.

\section{EU and South America: Reflections on the Theories and the Lessons}

In the first two sections of this article, our analysis was resolutely Euro-centric. Our (disputable) presumption was that, if South America were to move towards greater trans-national integration, it could learn from (and even imitate) the European pattern. Moreover, we have (surreptiously) defined integration in European terms, i.e. the process of "how and why they (national states) voluntarily mingle, merge and mix with their neighbors so as to lose the factual attributes of sovereignty while acquiring new techniques for resolving conflicts among themselves" (Haas 1971: 6). To this classical definition by Ernst Haas, we would only add that they do so by creating common and permanent institutions capable of making decisions binding on all members. Anything less than this-increasing trade flows, encouraging contacts among elites, making it easier for persons to communicate or meet with each other across national borders, promoting symbols of common identity-may make it more likely that integration will occur, but none of them is "the real thing."

Under these presumptions, as shown above, CAN and MERCOSUR have made little progress toward integration. There have been moments of regional cooperation, solidarity and identification, but they have not created an institutional legacy of much significance, nor have they succeeded in diminishing those "factual attributes of sovereignty" that Haas mentioned. Only by softening or changing the definition of what constitutes regional integration can it be said that significant progress has been made in this part of the world. 
It is sometimes claimed that there is a distinctive "Latin American" (or, for that matter, "Asian" or "African") pattern of integration that may not resemble the European "institutional" one, but nevertheless is capable of resolving regional problems, asserting regional cohesion and building regional identity. We disagree. We think this is a misleading overextension of the definition of "regional integration." Regional integration should be conceptually differentiated from simple, i.e., uninstitutionalized and usually erratic, regional cooperation or collaboration.

Assuming that regional integration is desirable in both CAN and MERCOSUR, but has made minimal progress so far, we in this section present a number of reflections on the existing theories of European integration and on European "lessons" with a view to developing specific proposals that might advance regional integration in South America in the near future.

\subsection{Reflections on the Theories}

Federalism is not likely to apply in South America for several reasons:

1. Some states (e.g. Brasil and Paraguay) have constitutions that explicitly prohibit any delegation of sovereignty to supranational institutions. Although this is not an insurmountable obstacle (constitutions may be amended), it is not negligible either;

2. In MERCOSUR, population asymmetries among member states would turn a prospective "federation" into the most hypertrophied ever. This is so because one of the basic principles of federalism, equality among federated units, makes unrealistic the democratic principle of equality among individuals whenever one of the units has more than half the total population. Brazil accounts for circa $80 \%$ of MERCOSUR's population, and it would still account for more than $50 \%$ if all of the remaining countries in South America were to join the bloc. In CAN, the main obstacle would be population heterogeneity rather than asymmetry: Bolivia, Ecuador and Peru are already torn societies as regard ethnic composition, and bringing them together would probably spread racial tensions rather than dilute them;

3. All federations require a "core" of stateness, and none of the South American countries seems prepared (yet) to concede such powers to a prospective regional government;

4. So, the threshold is simply too high. Only after fifty years of intensive cooperation and very extensive interdependence have the EU member states agreed to even begin to discuss the "Fword"-and they failed in their most recent and modest attempt to constitutionalize it.

Neither will "Regulation-ism" be an option in South America for the following reasons:

1. "Regulation-ism" only becomes relevant once the level and extent of economic and social interdependence is very high and both CAN and MERCOSUR are still far from either (Burges 2005);

2. Given the greater dependence upon "extra-regional" powers, South American countries are more likely to be compelled to conform to standards and norms elaborated and imposed by these "hegemons," i.e., by the US and the EU, or by specialized international institutions such as WTO and IMF. 
3. Regulatory politics across national borders depends heavily on three factors, none of which is consistently present across South America: (a) Reliable observance of the rule of law; (b) Relative autonomy and professionalism of state bureaucracies; and (c) "Epistemic communities" of specialized experts who share initial premises and operative procedures;

4. The efficacy of regulatory agencies in democratic countries depends crucially upon their being embedded in a broader context of political legitimacy that allows non-democratic groups of experts to take decisions binding on everyone because they can ultimately be held accountable by independent parliaments, commissions of inquiry, a free press and partisan competition. At the same time, these groups should be exempted from executive discretion, arbitrary financial restrictions and patronage politics. In most South American countries, these conditions are not guaranteed. Moreover, the dominant political rhetoric does not focus on a regulatory deficit at the regional level, but on an allegedly democratic one.

This leaves us with two potentially viable options for regional integration: inter-governmentalism and neo-functionalism. Both have their pitfalls and using either strategy will certainly be problematic, although our tentative assessment is that the former is less promising for the following reasons:

1. The "classic" (and apparently easiest) starting point for inter-governmentalism would be a "Free Trade Area (FTA)" or, even more ambitiously, a "Customs Union (CU)":

a. FTAs and CUs are notoriously difficult to negotiate sector by sector. They usually incorporate lots of derogations and exemptions, and the disputes they raise drain away most of the enthusiasm and integrative momentum -as the history of CAN and the last years of MERCOSUR testify.

b. Moreover, in the present global context where trade liberalization is on the broader agenda of organizations such as the WTO, there are limited benefits to be gained (also, due to the proliferation of "most-favored-nation clauses" in many bilateral trade treaties).

c. The "victims" of regional trade displacement are concentrated and often well-connected politically; whereas, the "beneficiaries" are quite dispersed and much less well-organized.

d. The "logic" of FTAs (but less so CUs) is to include as many "regional" partners as possible while the logic of effective regional/international integration is to concentrate on a small number of initial participants and to share the benefits among them first-and to expand only later.

e. There is no conclusive historical evidence that FTAs tend to become CUs and then turn into Monetary Unions or Common Markets. Previous experiments with FTAs in Latin America (Schmitter 1970b) suggest that—if they survive at all—they do so by encapsulating themselves and not by spillingover into wider arenas of policy-making. They may be easy to adopt (if sufficiently riddled with exemptions), but they are very unlikely to expand into monetary affairs or greater labor mobility or even to extend their "lessons of cooperation" into less closely related policy arenas.

f. FTAs seem to be particularly susceptible to problems with the size distribution of member states. The larger ones with greater internal markets are almost always accused of exploiting the small ones-especially in the "uneven" exchange between manufactured goods and raw materials. When size distribution coincides with level of development, i.e., when the largest member states are also the richest, the conflicts generated become even more difficult to manage; 
2. Inter-governmentalism is highly sensitive to the contradictory role of the hegemon. On the one hand, it (or they, if there is some sort of co-hegemony such as has existed with France and Germany in the EU) has to be interested in taking the lead and paying a disproportionate share of the costs; on the other hand, it/ they must be very careful not to be perceived as exploiting the others once an agreement is reached and has begun to generate its inevitably unequal flow of benefits. Why, then, should the hegemon-when it presumably could dominate a given region and simply impose its preferred rules-choose deliberately to underutilize its power resources and concede so much to its minor partners?;

3. Inter-governmentally based regional arrangements, provided they remain intergovernmental, are not very likely to lead to spill-overs and, hence, further integration-unless some external shock or exogenous condition intervenes. If governments only enter into such arrangements voluntarily and rationally, i.e. when they are fully conscious of their costs-andbenefits and have excluded all possible unintended consequences, they are highly unlikely to react to unsatisfactory performance or unequal distributions of benefits by agreeing to up-grade their commitments and draft a new more expansive treaty. Their response will probably be either to freeze their existing level of commitment or to withdraw from the arrangement altogether-as Chile did in 1976, when it withdrew from the Andean Pact.

So, our tentative assessment is that inter-governmentalism, especially in its extreme form of inter-presidentialism, is not so much impossible to imagine as much less consequential with regard to eventual regional integration. It would be relatively easy to accomplish in formal terms-treaties supposedly establishing free trade areas have been signed relatively frequently within and across world regions. But it would not make that much difference. Many of those free trade agreements were never fully implemented and, when they were, they rarely (if ever) led to highly levels of regional integration, which leaves us with neo-functionalism as the most promising (if not necessarily the most feasible) strategy for advancing integration in South America.

\subsection{South American Reflections on European Lessons}

\section{Regional integration is a process not a product.}

In pursuing regional integration in South America, as was the case with European integration, we should never assume that we know where we are heading. Not just la finalité politique but also les finalités economiques ou sociales are unknowable. The process of regional integration is uncertain and unpredictable. However, it must be peaceful, voluntary, and, most importantly, transformative. The process must change national states' motives and calculations, enlarge the functional tasks they accomplish collectively, expand the authority and capacity of supranational institutions, and stimulate interest associations and social movements across member states. In this regard, one of the major problems with FTAs and CUs is that they "seem" to be and may indeed be "self-contained." So-called "open regionalism" based on a series of FTAs does little or nothing to promote integration. In MERCOSUR, as has been repeatedly pointed out, rather than a finalité it is still crucial to find a focus (Bouzas 2002; MERCOSUR 2004), i.e., a clear agenda of priorities, methodologies, and schedules. The challenges CAN faces are still harder, as centrifugal forces (towards the US) and inner tensions put its very existence at stake -as Venezuela's breakout clearly shows. 


\section{Regional integration has to begin somewhere and the best place to do so under contemporary conditions is with a functional area that is of relatively low political visibility, that can apparently be dealt with separately and that can generate significant benefits for all participants.}

For regional integration to proceed, it is essential to promote collective resolution of concrete problems in a positive fashion. That is the main lesson proffered by the original functionalist theorist of integration, David Mitrany (1946). The task is not just about removing barriers-negative integrationbut also about creating common policies to regulate and distribute benefits-positive integration (Scharpf 1996). With regard to the distribution of benefits, the best one, of course, is Pareto Optimal when everyone wins and no one loses. But this is highly unrealistic. The distribution of benefits can be (and almost always is) disproportional at times, but it is critical to ensure a proportional or "fair" distribution over a longer period. Participating actors must be encouraged to think in terms of absolute rather than relative gains. It is crucial to select a functional area that is initially uncontroversial, "separable" and "interconnected." "Separable" means that the area must be capable of being dealt with alone and of generating sufficient benefits on its own. "Interconnected" means that the area must be capable of generating secondary effects that require attention and engender positive supportive coalitions across borders. Trade liberalization is a form of "negative" integration and is unlikely to produce "spill-over" effects and to contribute to regional integration.

In MERCOSUR, there was an early case of successful integration in the area of nuclear energy (Hirst and Bocco 1989; Milanese 2004). However, as was the case earlier with EURATOM, it did not generate spillover effects. For this reason, it will be critical to find the contemporary equivalent of "coal and steel" which is where the EU began in the early 1950s. This could be transport (one functional area) or, better, transport and energy (two highly interrelated functional areas). In the abstract, transport and energy seem to satisfy all the above-mentioned conditions, i.e., relatively low controversiality, separability, and interconnectedness. It is therefore encouraging that one of the most substantive projects recently launched, the above mentioned IIRSA, is focused specifically on these two functional areas. Moreover, it encompasses not only MERCOSUR all the South American subcontinent.

\section{Regional integration is driven by the convergence of interests, not by the formation of an identity.}

International regions do not exist, even where created and administered as such by a colonial power. Common language and religion do not seem to be of much help. On the contrary, as Hispanic America shows, such commonalities have not prevented fragmentation and conflict. We should be equally careful about the economists' notion of complementarity. Regional integration is an intrinsically dynamic process and generates unforeseen and emergent specializations and new divisions of labor among its participants. Hence, pre-existing trade patterns may not be a good indicator of the potential for generating new forms and levels of interdependence.

It is also important that nation states join with convergent-but not identical-motives. They should "hit on" integration for different reasons and with different expectations. This provides the future potential for making 'package deals' that will include a variety of pay-offs across participants. Also, there seems to be no automatic effect (à la Karl Deutsch) on integration of substantial increases in social communication across national borders. Decreases in communication may lead to separate identities, but increases do not necessarily produce integration. Contrary to the common notion, previously intense national antagonisms can be useful for integration-provided there is a strong motive for overcoming them. Something approaching a regional consciousness has certainly emerged after decades of rivalry and neglect. However, there is little evidence that this new consciousness is pushing forward regional 
integration. Identity or loyalty to the region as a whole is the eventual product of, not the pre-requisite for, integration. A lot, in other words, can be accomplished before a common identity or loyalty emerges. Cardoso (1997) recognized this point when he stated that South American integration was based on three pillars: trade and economic, physical, and energetic. Although he also referred to a regional identity and a political dimension, he mentioned them not as pillars but rather complementary elements of integration. This vision, however, was later questioned by the Lula administration.

\section{Regional integration may be peaceful and voluntary, but it is neither linear nor exempt from conflict.}

All the participants from the beginning must acknowledge the existence of conflicts. But this is not enough. They must also expect those conflicts to be resolved peacefully. Indeed, the existence of conflicts is inevitable and exploitable. Without conflicts, regional integration would not advance. Of much greater importance is the answer to the question: What is the method for resolving these conflicts? Who "cooks up" the winning formula? One of the tricks transferable from the European experience is to use the conflicts (usually over inequality in the distribution of benefits) to expand and not to contract the scope and level of common (supranational) regional authority. Many (but not all) conflicts can only be resolved by increasing the powers of the regional secretariat or expanding the scope of common activities (or both) with sidepayments to losers. The unanimity rule is crucial at the early stage to reassure potential losers (especially if they are very unequal participants), but tends to be transformed as the integration process advances. There are two typical ways of managing conflicts peacefully when they arise: either through formal or informal procedures. The former require some kind of institutionalization, especially regarding the rule of law through autonomous judiciary bodies; the latter may do without them. While formal procedures prevail in the EU, in South America it is the other way round.

\section{Regional integration should begin with a small number of member states, but should from that beginning announce that it is open to future adherents.}

The EEC originally started with six members, but was open to others. It should not be presumed that initial exclusion is definitive, although it is useful to have a small number in the beginning for decision-making and distributive purposes. Demonstration of "success" through subsequent enlargement is crucial. In choosing member states, there are two factors to consider: spatial contiguity ("core area") and relatively high initial exchange ("relative acceptance ratio"). The latter is important because it increases the "envy" of outsiders. The unanimity rule, along with tolerance, should be enforced when admitting new entrants. As well, deliberate ambiguity about "regional" boundaries is sometimes useful. MERCOSUR has from the beginning left an open door to the rest of LAIA members, and specifically promoted the accession of Chile at the soonest possible moment. The bloc's very name (featuring neither Southern Cone nor South America but just South, hence avoiding a definition as to how far north it could reach) was chosen in order to leave the question of future enlargement wide open. In its early years MERCOSUR accepted Bolivia and Chile as associate members, later took Peru, Colombia and Ecuador in with the same status, and finally integrated Venezuela. In December 2004 the South American Community of Nations (SAC) was founded in Cuzco, bringing together the twelve South American countries-five of MERCOSUR and four of CAN plus Chile, Guyana and Suriname.

\section{Regional integration inevitably involves national states of quite different size and power capability.}

The key interest cleavages in the process of integration tend to be based on relative size and level of development. These should be accommodated in institutional rules, e.g., by overrepresenting small countries and inserting special programs for less developed members. The best imaginable outcome is "convergence" whereby the weakest members in economic and political performance find themselves 
growing faster and becoming more secure relative to those that are stronger. The thorny issue is how to ensure that the latter agree to such a re-distribution of income and power. One central role in this process should be played by the adjudication process at the regional level (e.g., European Court of Justice). This helps to ensure that large actors do not dominant small ones. Also, the secretariat of the regional organization should play a proactive role in controlling initiatives and making coalitions that combine both the weak and the strong. Symbolic compensation should be made through such devices as an equal number of commissioners, a rotating presidency, and the location of regional institutions by over-favoring small states.

In MERCOSUR, the two smallest states (Paraguay and Uruguay) are highly vulnerable to economic volatility and political changes in their larger neighbors. Apart from stabilizing themselves, Argentina and Brazil will need to create mechanisms that redistribute the benefits of integration with a bias towards their weaker partners. A first step has been taken with the creation of FOCEM, a pool of structural funds that will be mostly financed by the larger member states and profited from by the smaller. For a change, CAN is at a more advanced stage in this dimension. The Secretariat, Court and Parliament headquarters are respectively located in Lima, Quito and Bogota, whereas the powerful Andean Development Corporation (CAF) is still based in Caracas.

\section{Regional integration, however, requires leadership, i.e. actors who are capable of taking initia- tives and willing to pay a disproportionate share of the cost for them.}

This is obviously related to the preceding issue of size and development. In the fortunate European pattern, the two cleavages (size and development) do not coincide, but cut across each other. Some small countries are rich and some large ones are (relatively) poor. In South America the situation is more complicated. The questions to be answered are: (1) Why will a hegemon or pair of hegemons be willing to pay the higher price for membership?; and (2) What can induce them to under-utilize their power advantage? In the case of a hegemonic duo, stability is important but sometimes brings awkwardness among late arrivers. On the other hand, a single "imperial" hegemon, even if "generous," can sometimes have an inhibiting effect-e.g., the US in NAFTA. However, Brazil's share of MERCOSUR and South America's population and GDP makes of it the natural candidate for leadership.

Hence, the debate over leadership has been unfolding in Brazil over the last two presidencies. While Cardoso and his foreign minister Luiz Felipe Lampreia considered that their country was not ready to pay the price, their respective successors, Lula and Celso Amorim, thought otherwise. They have supported a more decisive role for Brazil, both in the region and worldwide, and have pushed the integration agenda with greater intensity. This course of action may have been counterproductive. In the last three years, Brazil has not even been able to secure the support of all its MERCOSUR partners for any of its major international bids: nominating the secretary general of the WTO, appointing the president of the Inter-American Development Bank, and reforming the UN chart in order to gain a permanent seat in the Security Council. Venezuela under Hugo Chávez has also made efforts to build itself a leadership position in the region, taking advantage of the high international prices of its main commodity, oil. However, its militant stance has raised as much opposition as support among its neighbors. The relation between ambitions and capabilities has still to find the right balance in the region.

\section{Regional integration requires a secretariat with limited but potentially supranational powers.}

Key powers of the secretariat, in the case of EU, include: (1) control over initiation of new proposals; (2) control over distribution of positions within its quasi-cabinet (the European Commission); (3) budgetary discretion; (4) potential to take member states to European Court of Justice; (5) network position and possible information monopolies, especially with regard to sub- 
national actors (functional and territorial); (6) alliances with Euro-parliament; and (7) packagedealing and log-rolling potential. In CAN, the Secretariat is recognized by the treaties as the executive body of the bloc has been endowed with virtually none of the competences listed above. In MERCOSUR, the project to strengthen the secretariat by bestowing it with technical-in addition to administrative-competencies have had a good start but later fell short of expectations, and no regional institution has any of the powers listed above. Building up and funding a regional secretariat with effective powers and transparent procedures is advisable and has been frequently advocated (Peña 2006), but it is unlikely to happen in the short run.

\section{Regional integration requires that member states be democratic.}

That member states are democratic provides insurance that members will not use force against each other, especially once integration has progressed and their respective civil societies have become intertwined. Some guarantees of government legitimacy and of a "centripetal/centrist" tendency in partisan competition are also essential so that commitments remain not only constant across parties, but also deeply rooted in citizen expectations. In South America, the democracies are at different levels of regime consolidation. However, most of its leaders share a strong commitment to the link between democracy and regional integration. In MERCOSUR, this commitment became manifest in the Protocol of Ushuaia, which established a democratic clause, and in the resolute action taken by all member-states to support democracy in Paraguay in 1996-when it faced a serious threat-and later in neighboring Bolivia. In CAN, widespread support for democracy turned itself evident when Fujimori's Peru was excluded from several bloc arrangements after the self-coup of 1992.

\section{Regional integration seems possible with members that are at different levels of development and per capita wealth.}

The European experience not only shows that regional integration is possible for member national states with different levels of development but also clearly demonstrates that upward convergence is possible for poorer and less developed countries. In other words, integration not only can cope with national disparities at the point of departure, but also diminish them over time. MERCOSUR consists of four countries at different levels of development and per capita wealth. However, the main problem is that the level of development is not homogeneous within member states, what makes inter-state transfers difficult to justify in the eyes of the underprivileged that live in the contributor countries. This situation may require the enactment of policies whose benefits are also enjoyed by groups of the wealthier-larger members-an example of which is the less-thanfamous CAP in the EU. In the case of CAN, significant inter-state transfers did not take place when oil-rich Venezuela was a member, so there is little reason to expect that they will take place in the current conditions.

\section{Regional integration is basically an endogenous process, but it can be critically vulnerable to exogenous forces, especially in its initial stages.}

As evidenced by the European experience, external influence (read American) may be decisive in the early stages of integration. In South America, where the influence of the US has been traditionally greater as an aftermath of the Monroe doctrine, the tolerance and cooperation of the US would be essential for the success of any movement toward regional integration. So far, the US has been either supportive or indifferent to various integration projects in Latin America, but it is unlikely that it will keep such support or indifference with regard to the largest initiative at regional integration in the Western Hemisphere ever. In these circumstances, it is advisable not to confront but to engage the US in supporting South American integration by agreeing to simultaneously negotiate the continental agreement that it promotes. 


\section{Regional integration, at least until it is well established, is a consumer not a producer of international security.}

European integration was from the beginning predicated on the existence of a "security community" composed of democratic countries. MERCOSUR is not different in this regard: it only includes democracies, and violent conflicts among member states are excluded. Although Argentina and Brazil have historically conceived of each other as a rival, wars among them have not been waged since 1828-and their last processes of democratization have propelled mutual trust. If it is true that both countries, together with Uruguay, went to a bloody war against Paraguay between 1865 and 1870, violent conflict has been absent among the four MERCOSUR partners ever since and is currently unthinkable. The historical record in the Andean region is more blurred and some militarized inter-state conflicts have taken place in the XX century, but nowadays their repetition looks highly unlikely. In contrast, domestic violence (both criminal and political) is still a worrying feature in some of these countries.

The recent developments within the European Union involving the non-ratification of its Constitutional Treaty, within MERCOSUR with regard to the non-development of common institutions, and within CAN concerning its historical underperformance suggest that three more "lessons" should be added to the previous list:

\section{Regional integration may suffer from excessive or, at least, precocious institutionalization, as much as from an institutional deficit.}

Virtually all students of trans-national integration would agree that "institutions matter," but so does the timing of their creation and evolution. Lesson 8 helps to capture the paradox. The initial "secretariat" of a regional organization has to have some significant supra-national component if it is to play a pro-active role. Virtually by definition, this means that its founders have to behave "precociously" in the sense that they are "ahead" of the expectations of individual member states. Subsequently, however, the promoters have to become re-active and be assured that the further formal expansion of these institutions come in response to a widely perceived need for pursuing new activities and assuming new competences at the regional level. The neo-functional approach shows an awareness of this paradox and identifies time and timing as crucial intervening variables. Without setting a specific threshold, it does imply that spillovers are only likely to occur once processes of increased exchange among member states have become sufficient to generate new interests and new conflicts of interest, as well as mechanisms for collective action across national borders, Therefore, the decision to establish and subsequently to upgrade institutions cannot be disconnected from the process of integration itself and the unintended consequences it produces. The recent failure to ratify an ambitious Constitutional Treaty demonstrates, not only the poor sense of timing of its drafters, but also the more generic failure of EU promoters in the member countries to convince broad publics that there was a functional need for such an institutional expansion. MERCOSUR functioned reasonably well in its first years because it chose not to replicate the precocious and pretentious institutions of the Andean Pact. Had they tried to do so, their ineffectiveness would have inexorably eroded the legitimacy of the integration process as a whole. Granted that the under-development of common institutions cannot persist for long if regionalization is to move ahead, but reforms in their scope and authority must be "opportunistically" timed with regard to needs and perceptions. They certainly should not be chosen by merely replicating the practices of previous successful experiences with regional integration, i.e. the European one. 
14. Regional integration needs both formal agreements and informal arrangements, but as it proceeds rule-bound procedures based on publicly defensible principles should increasingly prevail over improvised settlements based on momentary distributions of power.

The EU has taken from its member states a highly institutionalized system of government. Democratically accountable national leaders make regionally-binding decisions through formal (if very complex and often little understood) procedures, and professionalized national bureaucracies are supposed to implement these decisions in a predictable (and identical) fashion. However, such a model of government and administration took a long time to develop and an even longer time to spread moreor-less evenly across its member states. Transferring this model to a region composed of less developed polities is problematic, all the more so when there is great deal of variation in state capacity and rule of law among these units. The initial mix between formal and informal transactions is much more imbalanced in favor of the latter and the integration process itself does relatively little to alter the situation. The real sources of power and conformity remain hidden and rarely match the formal prescription of competences in treaties and protocols. As a result, the impact of publicly announced and commonly agreed decisions is usually overestimated and, when revealed as such, contributes to disillusionment with the process of regional integration.

15. Similarly, all integration movements require a mix of both material payoffs to specific members and symbolic rewards for the region as a whole, but once they settle into routinized (and hopefully increased) transactions, the former should prevail over the latter.

In Europe, the exalted rhetoric of common cultural identity and purpose and international peace and solidarity rather quickly gave way to much more prosaic objectives and expectations-many of which were realized. Granted that the symbolic component was later revived (more or less in tandem with the pretense of constitutionalizing the process); nevertheless, the EU has never witnessed the mismatch between words and deeds that has become a standard characteristic of Latin American efforts at integration. The term "integration-fiction" has even been coined to denote this lack of realism concerning cause and effect, and this has contributed to making the general publics of member states skeptical of the value of regionalism.

\section{References}

Bonilla, Adrián. 2001. Entre el deseo y la ficción. Interdependencia e integración en la región andina. XXIII LASA World Congress, Washington D.C., September 6-8.

Bouzas, Roberto. 2002. MERCOSUR: ¿Crisis económica o crisis de la integración? Foro de Política Los nuevos desafíos para la integración regional', Bolsa de Comercio de Buenos Aires, Buenos Aires: CEI-INTAL.

Bouzas, Roberto, Pedro Da Motta Veiga and Ramón Torrent. 2002. In-Depth Analysis of Mercosur Integration, its Prospectives and the Effects Thereof on the Market Access of EU Goods, Services and Investment. Report presented to the Commission of the European Communities, Observatory of Globalization, Barcelona, November, http://mkaccdb.eu.int/study/studies/32.doc

Burges Sean W. 2005. Bounded by the Reality of Trade: Practical Limits to a South American Region. Cambridge Review of International Affairs, 18 (3): 437-454.

Burgess, Michael. 1989. Federalism and European Union: Political Ideas, Influences and Strategies in the European Community. London: Routledge. 
Cardoso, Fernando Henrique. 1997. BRASIL-ARGENTINA. Discurso do Senhor Presidente da República por ocasião do jantar que oferece ao Presidente Carlos Menem, da República Argentina. Brasília, November 10

Deutsch, Karl. [et al]. 1957. Political Community and the North Atlantic Area. Princeton: Princeton University Press.

Haas, Ernst B. 1958. The Uniting of Europe. Stanford: Stanford University Press.

Haas, Ernst B. 1964. Beyond the Nation-State. Functionalism and International Organization. Stanford: Stanford University Press.

Haas, Ernst B. 1971. The Study of Regional Integration: Reflections on the Joy and Anguish of Pretheorizing. In Leon N. Lindberg and Stuart A. Scheingold (eds.) Regional Integration: Theory and Research, pp 3-44. Cambridge, MA: Harvard University Press.

Haas, Ernst B. 1975. The Obsolescence of Regional Integration. Berkeley: Institute of International Studies.

Hirst, Monica and Héctor E. Bocco. 1989. Cooperação Nuclear e Integração Brasil-Argentina. Contexto Internacional, 5 (9): 63-78.

Hoffmann, Stanley. 1966. Obstinate or Obsolete? The Fate of the Nation State and the Case of Western Europe. Daedalus, 95.

Mace, Gordon. 1988. Regional Integration in Latin America: a Long and Winding Road. International Journal, 43 (3): 404-427.

Majone, Giandomenico. 1996. A European Regulatory State? In J. Richardson (eds.) European Union: Power and Policy-Making. London: Routledge.

Malamud, Andrés. 2003. Presidentialism and MERCOSUR: A Hidden Cause for a Successful Experience. In Finn Laursen (eds.) Comparative Regional Integration: Theoretical Perspectives, pp 53-73. London: Ashgate.

Malamud, Andrés. 2004. Regional Integration in Latin America. Comparative Theories and Institutions. Sociologia. Problemas e Práticas, 44: 135-154.

Malamud, Andrés. 2005a. Presidential Diplomacy and the Institutional Underpinnings of MERCOSUR. An Empirical Examination. Latin American Research Review, 40 (1): 138-164.

Malamud, Andrés. 2005b. MERCOSUR Turns 15: Between Rising Talk and Declining Achievement. Cambridge Review of International Affairs, 18 (3): 421-436.

Malamud, Andrés. 2005c. Spillover in European and South American Integration. A Comparative Evaluation. CIES e-Working Paper, N¹/2005. CIES-ISCTE, Lisbon.

Mattli, Walter. 1999. The Logic of Regional Integration. Europe and Beyond. Cambridge: Cambridge University Press.

MERCOSUR, Secretaria del. 2004. Un Foco para el Proceso de Integración Regional. Primer Informe Semestral de la SM. Montevideo, July.

Milanese, Juan Pablo. 2004. Supranacionalidad en el Cono Sur? Análisis de un caso inédito, ignorado y potencialmente paradigmático. I Encuentro internacional de Investigadores de la Red Latinoamericana de Cooperación Universitaria, Universidad de Belgrano. Buenos Aires, 11-12 March.

Mitrany, David. 1946. A Working Peace System. Chicago: Quadrangle Books.

Moravcsik, Andrew. 1998. The Choice for Europe: Social Purpose and State Power from Messina to Maastricht. London: UCL Press.

Peña, Félix. 2006. Los grandes objetivos del MERCOSUR (Zona de libre comercio, Unión aduanera y Mercado común): Elementos para apreciar progresos alcanzados en los primeros quince años del Mercosur como proceso voluntario de integración comercial y económica. Seminario 15 anos de MERCOSUL: avaliação e perspectivas, Fundação Memorial da América Latina, São Paulo, March 27-28. 
Scharpf, F. W. 1996. Negative and Positive Integration in the Political Economy of European Welfare States. In G. Marks, F. W. Scharpf, P. C. Schmitter and W. Streek (eds.) Governance in the European Union, pp. 15-39. Thousand Oaks, CA: Sage.

Schmitter, Philippe C. 1970a. A Revised Theory of Regional Integration. In Leon Lindberg and Stuart Scheingold (eds.) Regional Integration: Theory and Research. Cambridge, MA: Harvard University Press.

Schmitter, Philippe C. 1970b. Central American Integration: Spill-Over, Spill-Around or Encapsulation? Journal of Common Market Studies, 9 (1): 1-48.

Schmitter, Philippe C. 2004. Neo-Neofunctionalism. In A. Wiener and T. Diez (eds.) European Integration Theory, pp. 45-74. Oxford: Oxford University Press.

Vargas-Hidalgo, Rafael. 1979. The Crisis of the Andean Pact: Lessons for Integration among Developing Countries. Journal of Common Market Studies, 17 (3): 213-226. 